
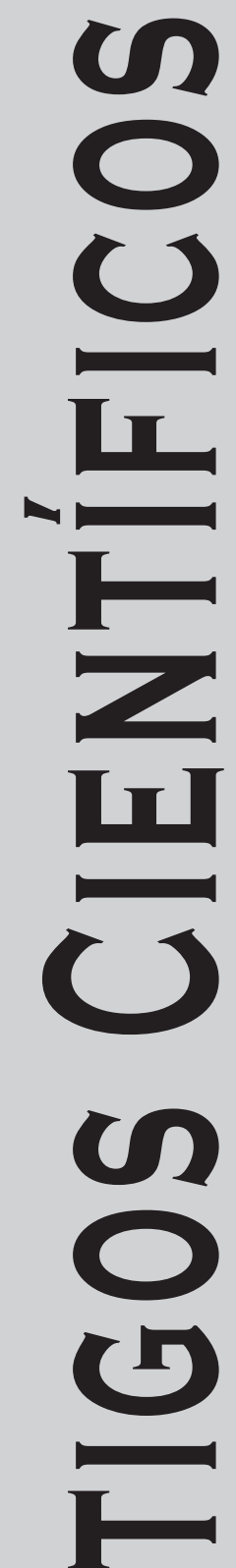
ac

Revista Música Hodie, Goiânia - V.14, 238p., n.1, 2014 


\title{
Projeto Destino Pirilampo: um Estudo sobre a Composição de Meta-Soundscapes em Música Ubíqua
}

\author{
Luzilei Aliel da Silva (Universidade Federal de São Carlos, São Carlos, SP) \\ luzaliel@gmail.com \\ José Eduardo Fornari Novo Junior (Universidade Estadual de Campinas, Campinas, SP) \\ tutifornari@gmail.com
}

\begin{abstract}
Resumo: Música ubíqua é aqui entendida como uma derivação natural da música eletroacústica na qual equipamentos eletrônicos são ubiquamente interconectados para juntos criarem música. Com este ambiente informacional, é atualmente possível fazer uma composição de paisagens sonoras (soundscapes) criada de material sonoro advindo de distantes e distintos soundscapes. Nós chamamos a este resultado de "meta-soundscape". Este artigo apresenta e discute o processo de criação e desenvolvimento da instalação de arte sonora intitulada "Destino Pirilampo" (DP) que explora esta premissa. DP é uma instalação performática multimodal desenvolvida para gerar meta-soundscapes (soundscape composto de diversos, distintas e distantes soundscapes). Esta explora a interação remota entre soundscapes cujo material é manipulado em tempo-real por um único performer. DP usa um aplicativo de VoIP (voice over internet protocol) para coletar e enviar dados sonoros dos soundscapes para o performer. Juntos, estes tornam-se agentes de um sistema aberto e complexo onde o significado estético emerge através de um processo de auto-organização. Sem utilizar sons gravado, DP cria um meta-soundscape interativo e artificial, que é um ambiente sonoro composto por um processo de música ubíqua contendo eventos sonoros sintetizados e naturais, manipulados em tempo-real pelo performer. Este trabalho é também um estudo de sonologia.
\end{abstract}

Palavras-chave: Soundscapes; Sonologia; Música eletroacústica.

Studying the Composition of Meta-Soundscapes in Ubiquitous Music

Abstract: Ubiquitous music is here understood as a natural derivation of electroacoustic music, in which electronic devices are now ubiquitously interconnected to make music together. With that apparatus, it is now possible to create a soundscape composition made of sonic material from distant and distinct soundscapes. We call that a metasoundscape. This article presents and discusses the process of creation and development of a sonic art installation entitled "Firefly Destination" (DP) that explores this premiss. DP is a multimodal interactive artwork developed to generate meta-soundscapes. It explores the remote interaction between soundscapes whose material is manipulated in real-time by a single performer. DP uses a VoIP application (voice over internet protocol) to gather sonic information from soundscapes and deliver it to the performer. Together they act as agents of a complex open system where aesthetical meaning emerges by self-organization. Without using recorded sounds, DP creates an interactive artificial meta-soundscape, which is a sonic environment built by a process of ubiquitous music composition of synthetic and natural sound events modulated in real-time by the performer. This work is also an study of sonology.

Keywords: Soudscapes; Sonology; Electroacoustic music.

\section{Introdução}

Atualmente, com os recursos tecnológicos disponíveis, é cabível ponderar sobre o quanto as distâncias geográficas ainda de fato nos separam. Sabe-se que as tecnologias digitais, de comunicação e informação, permitem a interação perceptualmente imediata de dados digitais de áudio, imagem e controle, entre indivíduos localizados em diferentes e distantes partes deste nosso planeta. Tal interação proporcionada pela tecnologia atual possui mediação eletrônica digital que, em muitos casos, ocorre sem mediação perceptual (a percepção consciente da existência de um atraso entre a transmissão e a recepção de uma mensagem, no caso, acústica ou óptica), porém sempre com mediação tecnológica, já que sempre existirá um atraso em qualquer tipo de comunicação, conforme definido em [Barbosa 2010]. Esta situação pode vir a criar, em determinadas circunstâncias, uma distonia perceptiva dos sentidos da visão e audição (que, por meio da tecnologia, podem atualmente processar informação remota em tempo-real), em relação aos outros sentidos, como o tato, o olfato ou 
o paladar (que não há atualmente tecnologia capaz de proporcionar que estes transponham o vinculo territorial, imposto pelos limites da localização espacial da ocorrência do fenômeno), Exemplificando, podemos assistir uma transmissão ao vivo de alguém preparando um bolo, onde podemos ver e escutar o cozinheiro perceptualmente sem atrasos, porém não podemos tocar, cheirar ou saborear o bolo, em tempo-real.

Entretanto, pode-se aqui sustentar que a interatividade audiovisual promovida pela tecnologia computacional é atualmente suficiente e bastante para, no mínimo, prover as urgências e os propósitos básicos da comunicação à distância. Na última década, a tecnologia convergiu para a produção em massa de sensores eletrônicos, fomentada pela sua miniaturização e queda de custo. Estes são equipamentos que convertem grandezas físicas em sinais eletrônicos discretos (digitais), tais como os: microfones (intermediados por conversores analógico-digitais); câmeras de vídeo digital; circuitos integrados de acelerômetros, giroscópios, bússolas; GPS (sistema de posicionamento global) e afins. Estes equipamentos permitem a aquisição de dados dinâmicos da localização, do movimento e dos gestos, que podem ser transmitidos remotamente, em tempo-real, de forma dinâmica e quase que instantânea. Exemplificando, pode-se atualmente transmitir os dados de um sensor de movimentos, como um acelerômetro, ou giroscópio, e possibilitar que dois indivíduos remotamente localizados joguem, em tempo-real, uma partida de pingue-pongue, mesmo ambos estando localizados remotamente. A interatividade destes novos sistemas de informação e comunicação parece convergir a propiciar a exploração de múltiplas mídias, tais como: som, gestos e informações visuais, que agem como peças estruturais para a possível construção de uma experiência multimodal imersiva, que pode promover a criação de um ambiente sonoro não limitado a uma única localização geográfica, mas que abrange, permeia e intersecciona distintos e diversos espaços sonoros remotamente distribuídos. A aquisição e a transmissão de dados multimodais, de forma perceptualmente imediata, permitiu a criação do projeto aqui apresentado, intitulado: "Destino Pirilampo" (DP). Este artigo abordará a exploração de possibilidades multimodais que podem ser geridas em três níveis de interação: 1) o som, 2) a imagem e 3) o gesto. O projeto DP tem como objetivo estender o conceito composicional inicialmente introduzido pela eco-composição, transcendendo, através da geração de meta-soundscapes (soundscape formado por diversos soundscapes, o efeito de source-bounding, conforme definido adiante.

Porém, os avanços tecnológicos ainda não são totalmente capazes de garantir que uma performance de música formal (aquela cuja boa execução depende, entre outros, da inexistência de atraso sonoro perceptível entre os interpretes, como, por exemplo, a execução de um quarteto de cordas) pudesse de fato atuar ao ser formado por músicos distribuídos em locais remotos, mas atuando juntos, numa performance musical mediada por recursos computacionais. Até o momento, diversas experiências nesse sentido foram elaboradas, como as performances remotas exibidas na série de vídeos, intitulada "Virtual Choir", de Eric Whitacre (disponíveis no link: https://www.youtube.com/user/EricWhitacresVrtlChr). Entretanto, tais experiências ainda parecem estar em seus estágios iniciais de desenvolvimento, ainda necessitando de uma grande quantidade de edição, pós-produção e acertos manuais, para exprimirem seu conteúdo estético, e mesmo assim, por não ocorrerem em tempo-real, ainda se submetem ao inexorável atraso de transmissão digital presente em qualquer comunicação de dados online.

Como sugerido, um grande problema para a interatividade remota computacional em performances musicais - especialmente para a música formal, conforme definida acima - é o atraso, também chamado pela engenharia de processamento digital de sinais de "latência”. Este fator é especialmente percebido em interações separadas por grandes distâncias 
físicas. A latência ocorre devido ao limite físico do intervalo temporal que a informação sonora necessita para viajar entre a sua fonte de geração acústica e a sua recepção (o ouvinte). De acordo com [Fornari, 2010], este é um dos elementos que podem ter contribuído para que a orquestra clássica, ao longo de sua evolução histórica, alcançasse um limite específico em termos de tamanho de sua distribuição física, dado pelo espalhamento e disposição geográfica dos músicos que compõem uma orquestra convencional, e assim, do tamanho dos palcos construídos especialmente para atender a tais performances musicais. Este limite é de aproximadamente 34 metros. O som leva cerca de 1/10 de segundo (100 m/s) para viajar 34m no ar, em condições normais de temperatura, pressão e umidade. Este é aproximadamente o intervalo de tempo requerido para que o sistema auditivo perceba conscientemente o atraso na comunicação sonora, criando efeitos acústicos tais como a reverberação e o eco. Este foi nomeado de LIS (Limite de Interatividade Simultânea). Qualquer comunicação sonora entre músicos (que normalmente necessitam de um alto grau de sincronização durante uma performance) separados por uma distância maior do que LIS (34m) tenderá a gerar déficits de sincronização, devido à ocorrência da percepção do atraso na cooperação performática.

Seguindo este mesmo princípio, para interações entre músicos através da internet, a ocorrência de latência, apesar da distância entre os interpretes, propõe um limite similar ao LIS. Consequentemente, problemas similares de sincronização musical podem ser encontrados até mesmo em interações remotas. De acordo com [Barbosa 2010], mesmo considerando uma situação hipotética em que alguém tenha conseguido acesso à maior velocidade possível de processamento de dados, em determinadas circunstâncias, um atraso significativo de comunicação ainda seria percebido. Este autor menciona que, mesmo considerando a mais rápida comunicação possível numa ligação ponto-a-ponto (peer-to-peer) entre dois indivíduos localizados em lados opostos do nosso planeta, estes estariam separados por uma distância de cerca de $20.000 \mathrm{Km}$, correspondente à metade da distância da circunferência terrestre, que é de cerca de $40.000 \mathrm{Km}$. Mesmo que os dados dessa hipotética interação fossem transferidos na velocidade da luz (cerca de $300.000 \mathrm{Km} / \mathrm{s}$ ), a latência perceptual ainda assim estaria presente, a qual iria ser de aproximadamente 133,4 ms, que é maior do que o tempo correspondente para transpor o LIS (100ms), e que assim implicaria em distorções de sincronização entre músicos numa performance realizada em tais condições, que dependesse da sincronia para a sua atuação.

Tal fato nos faz concluir que não há uma maneira possível de evitar a ocorrência de latência nas interações musicais remotas. Devido a esta constatação, algumas pesquisas recentes, em performances de música eletroacústica, ao invés de tentarem evita-la, utilizam a latência como mais um elemento estético no desenvolvimento artístico e exploração computacional [Traub 2005]. Considerando este contexto, o trabalho aqui apresentado também não busca superar a intransponível latência, mas sim minimiza-la, produzindo uma comunicação sonora dinâmica e em tempo-real. O projeto DP desenvolve um modelo sonoro interativo que incorpora a inexorável barreira da latência, presente em qualquer comunicação remota. DP não depende da sincronização entre os seus agentes formantes, uma vez que o resultado final é a criação de um meta-soundscape; aqui definido como um soundscape (paisagem sonora) produzido por múltiplos, distantes e distintos soundscapes, o qual é uma forma de arte sonora que não dependente particularmente da sincronização de seus agentes, como acontece normalmente no caso de música tradicional formal. Uma definição detalhada de soundscape pode ser obtida em [Truax 1992].

Com isto, este trabalho também alinha-se ao campo da Sonologia. Este é um termo atualmente adotado por pesquisadores e instituições brasileiras e internacionais - como o Institute of Sonology, no Royal Conservatory of The Hague ${ }^{1}$ - para fazer referência a um cam- 
po híbrido de pesquisas musicais, onde o som é estudado como o elemento permanente entre diversas áreas do conhecimento, tal como a: acústica, psicoacústica, cognição, análise, composição e performance musical.

A seção seguinte descreve o projeto artístico DP; a instalação artística e suas relações com os conceitos de eco-composição [Keller 1999; Keller 2000; Lockhart e Keller 2006] e paisagem sonora, ou soudscape [Truax 1992].

\section{O Projeto DP}

O principal objetivo do projeto Destino Pirilampo (DP) é possibilitar a exploração e promover a interatividade na manipulação de eventos sonoros vindos de soundscapes remotamente distantes, através da transmissão de dados para um único performer que orienta o processo generativo. $\mathrm{O}$ motivo que inspirou o nome deste projeto foi comparar o único performer com uma fonte de luz que atrai insetos voadores; no caso, eventos sonoros. Há ainda, como fonte inspiradora, a teoria do "efeito borboleta", de Lorenz (explicada em detalhes mais adiante) onde crê-se que um sentido estético sonoro pode vir a emergir de um ambiente informacional inicialmente caótico. A licença poética aqui utilizada se baseia na seguinte suposição: se um inseto voador, quando atraído em direção a uma fonte de luz, eventualmente encontra a sua própria morte; um pirilampo (vaga-lume), que tem em si uma fonte luminosa, ao ser atraído para uma fonte de luz maior, encontra a si próprio. O performer é aqui representando pela metáfora da "fonte de luz", que atrai, manipula e transmuta objetos sonoros (os "pirilampos") vindos de distantes paisagens sonoras e formando assim um meta-soundscape. Isto tenta representar metaforicamente o retorno dos eventos sonoros, dos soundscapes remotos, a um estado similar ao de suas origens, ou seja, um novo soundscape. A estruturação deste meta-soundscape, através da interação cibernética entre performer e modelo computacional, é dada pela realimentação sistêmica e controle de eventos sonoros gerados espontaneamente pelos soundscapes naturais. Porém, o meta-soundscape gerado apresenta uma sonoridade única e ubíqua, que transcende a limitação artística do tempo-espaço, uma vez que tal meta-soudscape não habita um local físico ou tempo sincrônico, mas um local virtual e atemporal; o ambiente adimensional do cybespace.

O performer rege o desenvolvimento dessa nova sonoridade através de gestos lúdicos e intuitivos. O sistema possibilita o performer explorar e desenvolver um repertório de gestos, transformando dinamicamente o conteúdo sonoro das múltiplas entradas de objetos sonoros. Este conceito centra-se na correlação do áudio remoto com a animação gráfica, ambas geradas em tempo-real. Esta compõe o apoio visual da criação e mediação do áudio digital de múltiplos agentes.

Barreiro e Keller (2010) propõem que as criações musicais ou atividades sonoras podem ser inseridas numa das três seguintes categorias: 1) atividades individuais sem resultados sonoros diretos; 2) atividades individuais almejando resultados imediatos audíveis; e 3) a interação social por meio da participação ativa de múltiplos usuários. Esta última categoria pode vir a implicar na interação entre os indivíduos imersos em suas paisagens sonoras. Estes poderiam promover novas formas de ação a partir da realização ou do ajuste de si próprios como agentes num novo ambiente. Em DP, o ambiente pode ser apontado como um conteúdo originado a partir de suas possíveis interações sonoras. Grande parte do material sonoro essencial para a construção deste soundscape vem desta forma de interação. A reciprocidade ocorre no cybespace, quando os participantes (no papel de agentes) enviam conteúdos na forma de áudio em tempo-real que são processados e controlados num único ambiente, onde o artista e o público estão localizados, criando assim um meta-soundscape. 
No escopo do modelamento ecológico, existem dois tipos de estratégias relatadas de interação entre o compositor e o ouvinte: 1) a aplicação de nichos artificiais (aqueles que não são encontrados na natureza) e 2) a exploração de "affordances" naturais (canais naturais de interação entre os seres humanos e nichos ecológicos) [Barreiro e Keller 2010]. Tais formas de percepção podem surgir a partir de vários fatores, tornando a experiência sonora única. O processo criativo de DP está relacionado com a interação entre ouvinte e compositor, permitindo a coleta de informações de nichos ecológicos naturais para a produção de meta-soundscapes artificiais. No limiar de tal permuta processual, o resultado sonoro pode apresentar características originais, enquanto que, contextualmente, este permanece sendo cognitivamente semelhante, o que é uma condição que satisfaz os princípios fundamentais das paisagens sonoras e da eco-composição.

\section{Do Soundscape à Eco-composição}

Alguns estudiosos analisam a música eletroacústica a partir de três perspectivas distintas: 1) o compositor, 2) o material sonoro e 3) o processo criativo. A música acusmática, que prima pela busca e utilização de aspectos fundamentais do som - colocando-os aparte de qualquer referência ou contexto além dos aspectos sonoros intrínsecos - descende diretamente do pensamento schaefferiano e se concentra principalmente na figura do compositor [Chion 2009]. Neste tipo de abordagem, o material é compilado e tratado dentro da estética almejada pelo compositor. Desse modo, a música acusmática pode ser definida por uma postura estética que se baseia na compreensão da mente do compositor, atuando com um arquiteto supremo, absoluto e inquestionável de todas as decisões composicionais de sua obra [Barreiro e Keller 2010], tal como pode ser observado nas obras de John Cage, Iannis Xenakis e Karlheinz Stockhausen. A postura de colocar o compositor em primeiro plano à sua obra contrasta com outras abordagens composicionais, tais como a composição de paisagens sonoras, ou soundscapes [Schafer 2001].

Ao contrário da música acusmática, a composição de soundscapes concentra-se principalmente no material sonoro. Este tipo de composição teve inicio na Simon Frayser University, localizada no Canadá, onde o compositor e educador Murray Schafer, junto com outros compositores, criou o "World Soundscape Project”. Foi Schafer quem cunhou o neologismo Soundscape (paisagem sonora), seguindo uma associação das palavras "paisagem” (landscape) e "som" (sound), substituindo a palavra "land" (região) de "landscape", por "sound". A composição de soundscapes prima pela inclusão de material sonoro inicialmente considerado como "não-musical” na criação musical contemporânea [Keller 2004], bem como a classificação de qualquer meio físico como possível gerador espontâneo de sons [Schafer 1997]. Paisagens sonoras naturais são geradas por múltiplas fontes sonoras naturais, que podem ser representadas como os agentes externos de um sistema aberto e complexo que apresenta propriedades emergentes de auto-organização de significado sonoro.

Através do processo de auto-organização, um contexto sonoro pode vir a emergir deste sistema, indicando aspectos perceptivos que caracterizam as regularidades e distinguem uma paisagem sonora de outra, tornando a informação acústica singular e continuamente original, já que esta de fato nunca se repete. Entretanto, este ambiente sonoro é auto-similar, ou seja, apresenta a reexposição, ao longo do tempo, de características sonoras que são perceptualmente similares entre si. Por esta razão, gerar um soundscape artificial, ou mesmo propor métodos de sua composição de fato (e não a mera utilização de trechos de gravações do seu áudio, numa forma de colagem sonora) não é uma tarefa trivial. Soundscapes 
são entidades sonoras dinâmicas e elusivas. Uma vez registrada, na forma de um arquivo de áudio, a paisagem sonora de fato deixa de existir. A gravação de uma paisagem sonora é apenas um registro imaterial do seu fenômeno sonoro; do mesmo modo que uma fotografia é apenas um registro visual de uma paisagem, e não a paisagem em si. Uma vez finalizada, a paisagem sonora não mais se repete. Aquilo que foi gravado, é o registro de um fenômeno auditivo dinâmico, cognitivamente semelhante e acusticamente único. Entretanto, o termo "composição de paisagem sonora" normalmente se refere a uma forma de composição que utiliza como material, sons gravados de paisagens sonoras diversas.

Uma alternativa ao método tradicional de composição de paisagens sonoras é o método denominado de Eco-composição. Este sistema é baseado na organização dos fragmentos de áudio de uma paisagem sonora, em estruturas modulares que formam assim uma peça musical (ou de arte sonora). A eco-composição cria estruturas composicionais usando conceitos simples, como a modulação e a acumulação de material sonoro. Por meio da interatividade, o compositor (ou mesmo os ouvintes) podem se adaptar dinamicamente à estrutura de composição de uma peça musical dessa natureza, criando uma experiência de audição que visa envolver o ouvinte, possibilitando-o que também este seja um dos agentes compositores deste ambiente sonoro. Essas são características fundamentais da eco-composição, que foca no processo composicional, ao invés de primar pelo material sonoro (como na composição de paisagens sonoras) ou pelo compositor (como na música acusmática).

Este trabalho tem como objetivo estender o conceito composicional inicialmente introduzido pela eco-composição. O projeto DP oferece uma possibilidade de entrelaçar dinamicamente materiais de paisagens sonoras oriundos simultaneamente de locais distintos e distantes. Ao invés de usar sons gravados, DP usa o streaming de áudio digital coletado diretamente da geração dinâmica das paisagens sonoras. O performer recebe esta mistura contrastante de eventos sonoros de distintos soundscapes e os manipula através da intervenção de um modelo computacional em ambiente Puredata, controlando através de dados gestuais a criação de uma nova paisagem sonora gerada por elementos das paisagens sonoras remotas, deste modo transcendendo o conceito de "source bonding" (traduzido aqui como "pregnância à fonte sonora”), conforme definido em [Smalley 1990]. Este conceito trata do viés cognitivo automático, ou gestaltico, que imediatamente associa eventos sonoros às suas respectivas e prováveis fontes sonoras. Tal ligação contextual pode ser entendida como um fluxo informacional entre objetos sonoros e suas respectivas origem generativas. Em DP, este fluxo é guiado pelo interprete que, por vezes, torna esta associação clara, enquanto que em outros momentos, tal associação torna-se difusa, perdendo a ligação referencial entre o som e a sua origem. Esta nova paisagem sonora é aqui chamada de meta-soundscape. Tem-se assim, no projeto DP, um processo de composição dinâmica onde o fluxo informacional viabiliza a emergência de novos significados sonoros para a percepção e a compreensão desta obra de arte sonora computacional. Tais significados necessariamente condensam-se num conjunto de conceitos cognitivos em comum, entre compositor/performer e os ouvintes, o que permeia esta obra e o seu público. Assim como na linguagem verbal, onde o significado semântico das palavras e suas estruturas sintáticas apenas podem ser entendidas se o ouvinte conhece a estrutura da linguagem, em artes sonoras não-verbais como DP (onde não existe referência sintática ou semântica) é essencial que os ouvintes tenham um conhecimento a-priori da comunicação sonora que está sendo elaborada e desenvolvida [Denora 2000].

Como visto, a interação é parte fundamental da proposta da eco-composição, mesmo na interação coletiva, onde a figura de um único compositor centralizador torna-se difusa ou mesmo inexistente. Em tais condições, materiais, métodos, formas e a audiência, são as partes essenciais que integram esse processo de composição, tornando a experiên- 
cia deste ato performático altamente significativa para os esforços artísticos [Keller 2004]. Encontra-se no método de criação sonora de DP uma proposta em aberto, validando mudanças entre agentes e objetos em locais remotos, transcendendo assim os limites geográficos do espaço e do tempo. DP expande o conceito de eco-composição, permitindo a comunicação entre os agentes e objetos, separados fisicamente, manipulando-os e transpondo o obstáculo usual imposto à criação musical, por sua permanência numa única localização espaço-tempo. Em suma, DP visa criar um meta-soundscape através de material sonoro adquirido de sons naturais distantes e distintos, onde o performer, como agente que angaria e manipula toda a informação sonora coletada dos soundscapes, guia a geração auto-organizada dessa nova paisagem sonora (o meta-soundscape), criada pela manipulação lúdica e interativa de múltiplas dimensões de sonificação, aproximando assim DP dos processos composicionais da música ubíqua.

\section{DP e a Música Ubíqua}

Em termos gerais, música ubíqua é aquela desenvolvida através da interação de múltiplos usuários conectados entre si por meios tecnológicos, utilizando uma ampla gama de métodos eletrônicos digitais para a comunicação de informação [Pimenta et. al. 2009]. Este conceito está relacionado com a fusão entre a computação e o meio ambiente natural, conforme proposto por Mark Weiser, em meados dos anos 1980 [Weiser, 1991]. Pode-se dizer assim que a música ubíqua é proveniente do contexto da computação ubíqua aplicada à música, onde o advento da computação móvel, a independência e a interconexão de dispositivos heterogêneos, a infraestrutura sem-fio (que possibilita penetrância e permeabilidade informacional), a conscientização conceitual, a mobilidade e a portabilidade, são todos cooperativos e complementares, objetivando uma incorporação generalizada de métodos e modelos tecnológicos que constituem um ambiente cibernético. Estas associações tendem a permitir a constituição de uma rede dinâmica de interações entre agentes, objetos e ambientes [Radanovitsck 2011].

No projeto DP, todas as áreas mencionadas acima foram compreendidas, conforme é explicado a seguir. As maciças sonoridades contidas em paisagens sonoras naturais são recebidas, manipuladas e sintetizadas pelo intérprete. Esta estrutura tende a ser guiada por um controle intuitivo, uma vez que tais eventos sonoros possuem um elevado grau de aleatoriedade e imprevisibilidade. Por exemplo, se um dos agentes está localizado num parque, e envia continuamente o seu conteúdo sonoro para o performer de DP; se subitamente, um pássaro ao redor começa a silvar, este será um evento imprevisível (e talvez de improvável repetição) para o interprete que recebe remotamente toda a informação e manipula os eventos sonoros no meta-soundscape. Os elementos e eventos caóticos que constantemente permeiam a produção sonora de DP referem-se ao conceito de auto-organização, conforme explicado a seguir.

\section{Do Efeito Borboleta à Auto-Organização}

O efeito borboleta é um termo comumente utilizado para se referir à teoria desenvolvida por Edward Lorenz, em meados de 1962, que trata de modelos matemáticos para uma determinada classe de movimentos caóticos. Lorenz, um meteorologista, constatou que em determinadas circunstâncias, pequenas variações nos parâmetros de determinadas equações matemáticas (tais como algumas equações utilizadas na predição de aspectos climáticos) podem ocasionar resultados imprevisíveis, impossíveis de serem determinados ou anali- 
sados objetivamente. Os efeitos dessas mudanças são tanto quantitativos quanto qualitativos. Estas observações levaram Lorenz a cunhar a celebre frase: "o bater de asas de uma borboleta de um lado do planeta pode desencadear um tufão do outro lado" (a butterfly flapping its wings in one part of the world might ultimately cause a hurricane in another part of the world).

Sistemas caóticos têm como princípio fundamental o grau de desordem (entropia), onde tanto a ordem quanto à desordem são considerados como válidos aspectos sistêmicos. [Naveira 1998] propõe que a teoria do caos seja entendida como uma possível alternativa para a formalização matemática, onde os resultados são, em teoria, perfeitamente previsíveis, e a incerteza de modelos estocásticos, onde as ocorrências de eventos que não podem ser previstos, são normalmente descartados. Deve-se entender que a utilização do termo "caos", que comumente é associado a distúrbios, é de fato enganosa. Na teoria do caos, o termo "caos" não é necessariamente associado à desordem, mas à "ordem mascarada de aleatoriedade” [Naveira 1998]. Este conceito é utilizado em DP. Todo o material enviado via internet é considerado como importante e válido, enfatizando-o não como desordem ou mero erro, mas como uma ordem codificada, disfarçada em aleatoriedade. Como explicado na seção 2, o próprio título do projeto DP (“Destino Pirilampos”) é baseado nesta premissa estética, associando o bater das asas de um inseto (no caso, um pirilampo) com a emergência de ordem, onde o o efeito final, não é apenas organizado, mas também independente e distinto do resultado (tufão) à soma de suas causas (o bater das asas da borboleta).

O recurso de organização espontânea de um fluxo caótico de dados desvenda a informação significativa anteriormente como que disfarçada de caos, o que é aqui entendido como um processo de auto-organização; onde um sistema complexo e aberto produz a emergência espontânea de regularidades que são posteriormente percebidas como significado [Ashby 1947]. Este conceito se entrelaça e avizinha à vários outros conceitos usados na contemporaneidade, tais como: as organizações em rede, as equipes autogeridas, e a aprendizagem organizacional; conforme definidos em [Naveira 1998]. Relacionando música com auto-organização, [Furlanete; Manzolli 2005] apresentou uma proposta de criação de um jogo sonoro em rede que possuía a premissa de conectar vários indivíduos afins que os mesmos possam se comunicar sonoramente. Estes eventos ocorrem através de ciclos reflexivos e retroalimentados. Estes são definidos pela: 1) maneira pela qual o compositor inicia sua obra, 2) o número de ciclos da interação sonora, 3) forma musical que gradualmente emerge. [Manzolli 1996] ressalta que a auto-organização no processo composicional tende a tornar-se uma vantajosa ferramenta uma vez que permite que a espontaneidade faça parte do processo criativo, como um dos aspectos estruturais do sistema. Isto permite a adaptação dos modelos computacionais interativos para serem incorporados como agentes auto-organizadores do sistema, numa forma eficiente de aumentar a autonomia criativa do compositor. Sistemas de composição com base em modelos interativos, como aquele definido em [Mazzolli 1996], referem-se particularmente ao aspecto da interatividade, desconsiderando a magnitude ou a duração dos eventos sonoros. O que se valida assim é a dinâmica da composição e suas fusões temporais. Isso acontece no campo musical quando a figura do compositor e a do intérprete se fundem num único agente composicional, o que permite que as estruturas formais interativas e gestuais (ou improvisacionais) intercorram e cooperem [Manzolli 1996].

\section{Métodos e Resultados}

O modelo computacional de DP foi desenvolvido no ambiente de programação Puredata, também conhecido como Pd (www.puredata.info) inicialmente desenvolvida por 
[Puckette 1996]. Pd é uma plataforma de programação visual de código aberto (open-source), multiplataforma (Linux, OSX e Windows) e gratuita, que viabiliza a criação de algoritmos (chamado em Pd de "patch") para: o controle, a análise, a transformação e a síntese de dados multimidiáticos (áudio, vídeo, controle, etc.) em tempo-real. Para o desenvolvimento computacional do projeto DP, inicialmente foi utilizada a versão $P d$-extended instalada no sistema operacional Linux. Entretanto, devido a problemas técnicos que impediam a comunicação de dados do áudio com o modelo computacional de DP, este foi instalado no sistema operacional Windows. Todo conteúdo do software Pd funciona a partir dos patches. Patches podem ser considerados estruturas pelas quais os algoritmos são desenvolvidos, gerenciados e controlados em Pd. Estes utilizam à manipulação de objetos (conteúdos singulares ao software Pd) para o desenvolvimento dos algoritmos desejáveis pelo desenvolvedor. Para o projeto DP, três patches foram construídos, juntos estes abrangem todas as seis áreas de música ubíqua, conforme detalhado na seção 4.

O primeiro patch (Figura 1) foi desenvolvido com o intuito de gerar e manipular objetos gráficos (formas geométricas ou estruturas lineares), associados aos aspectos sonoros recebidos, que se modificam dinamicamente em termos de formas e cores, criando uma associação com os dados de áudio recebido e os dados gestuais. Ou seja, quando o som recebido através do software voip e as imagens captadas pela webcam são introduzidos no patch número 1, as variações deste conteúdo podem alterar os comandos algorítmicos dos objetos gráficos, os tornando conteúdos mutáveis, dependentes das variações sonoras.

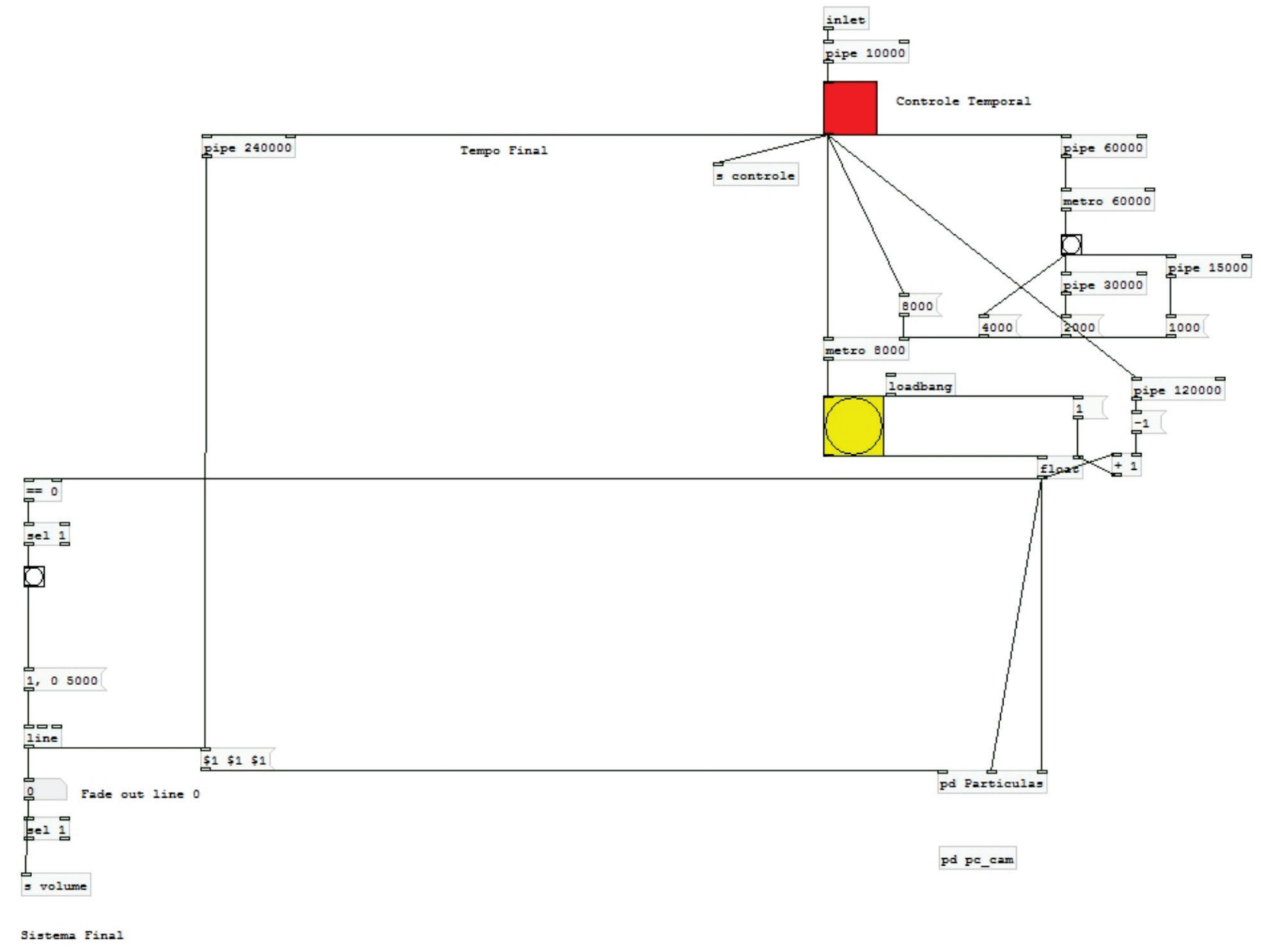

Figura 1: Imagem do primeiro patch do projeto DP. 
Desse modo, o primeiro patch também contém o módulo de aquisição de dados gestuais que são coletados em tempo-real a partir de gestos do performer (ver Figura 2). Eles são dinamicamente capturados pela webcam de um laptop comum, onde o Pd é executado. Durante o procedimento foi utilizado uma webcam comum, imbuída no notebook, que trabalha diretamente com algoritmo desenvolvido em Pd (Figura 2). A Figura 1 e 2 demostram o conteúdo produzido para o primeiro patch do sistema em sua forma detalhada, sendo possível, caso necessário, sua reutilização em outros sistemas.

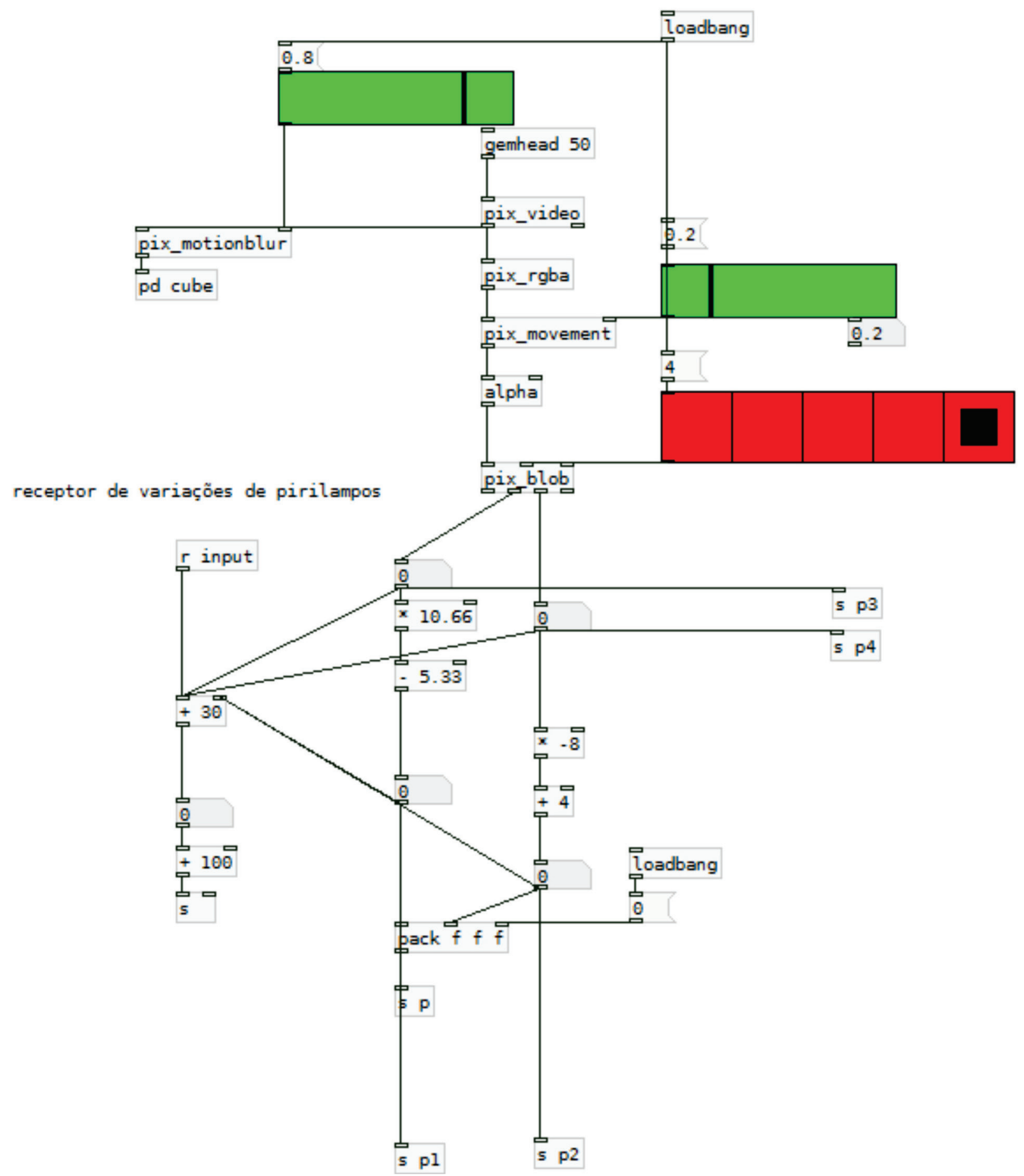

Figura 2: Imagem do patch da captação dos gestos através do webcam.

A interface gestual aqui utilizada não se baseia num sensor em contato direto com o performer, mas apenas lê os gestos à distância. Por este fato, esta é chamada de interface 
gestual imaterial, conforme descrita em [Fornari 2012]. Tal interface permite que o performer explore o controle intuitivo do processo, mantendo a liberdade de movimentos e exploração gestual lúdica. A figura abaixo apresenta um momento desta performance.

O segundo patch é um modelo computacional de síntese sonora subtrativa dinâmica que emula sons contínuos e ruidosos, como o característico som de vento ou de ondas do mar. Para isto foi utilizado um objeto do Pd que cumpre a função de um gerador de ruído branco (ver na Figura 3, o objeto “noise ”). O áudio produzido por este objeto foi, em seguida, processado por outro objeto que implementa o algoritmo Chamberlin de filtro de estado-variável. Este implementa 3 filtros simultâneos: passa-baixa, passa-alta, passa-faixa, e rejeita-faixa (ver o objeto "svf "). No caso deste patch, utilizou-se apenas a saída correspondente ao filtro passa-baixa (low-pass). Este modelo de síntese visa proporcionar uma sonorização para o streaming de áudio digital, dinamicamente controlado, coletado de múltiplas paisagens sonoras.

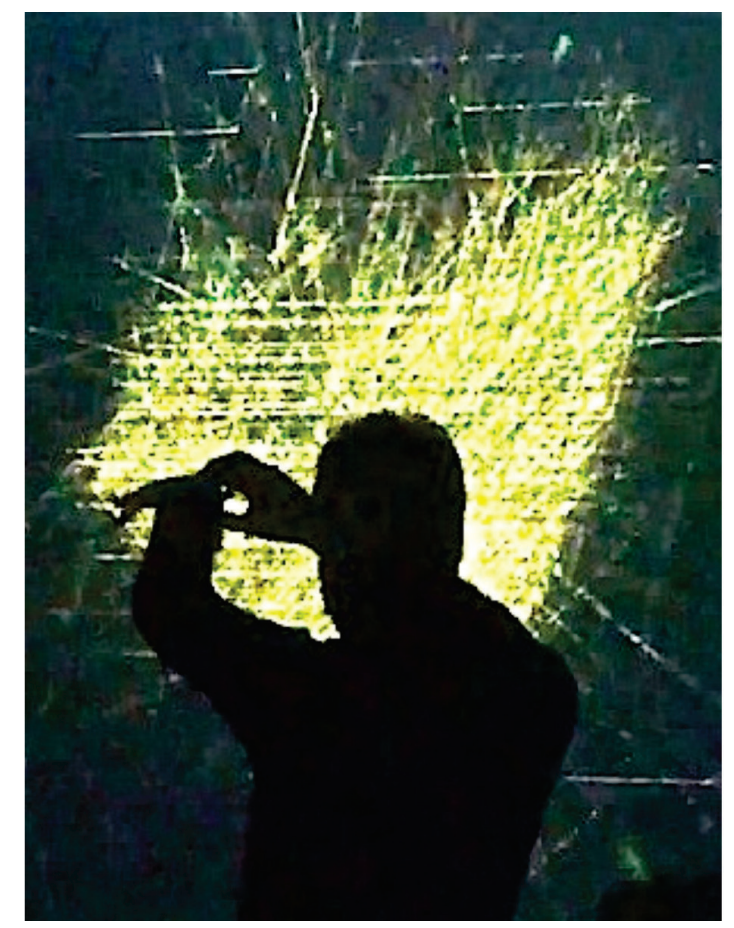

Figura 3: Imagem de um momento da performance do projeto DP, detalhando um gesto do interprete, que controla a geração sonora e também gráfica, observada na estrutura verde-amarelo ao fundo. Esta é gerada dinamicamente pelo modelo computacional contido no primeiro patch.

Devido à inesperada característica de variação de dados de áudio deste sistema, foi necessário elaborar uma estratégia que ajudasse a manter o conteúdo sonoro mais interessante durante toda a performance. Observou-se durante os testes que ocorriam momentos onde o fluxo de áudio mantinha-se pouco intenso ou pouco variante, tornando a performance monótona. A maneira de minimizar este efeito foi a utilização do módulo de síntese sonora subtrativa, que gera sons parecidos ao "som de vento". Isto propiciou maior apelo estético à performance, intercalando-se ao áudio proveniente das paisagens sonoras e permitindo assim com que este se tornasse mais inerente e contextualizado ao resultado sonora da peça; o meta-soundscape. O som sintetizado é controlado pela intensidade dos gestos do interprete (conforme visto na Figura 3). Dados destes gestos são coletados pela câmera de vídeo do laptop, que alimenta o modelo computacional do primeiro patch (Figura 1 e 2), funcionando este como uma interface imaterial. Detalhes da implementação desta interface podem ser encontradas em [Fornari, 2012]. 


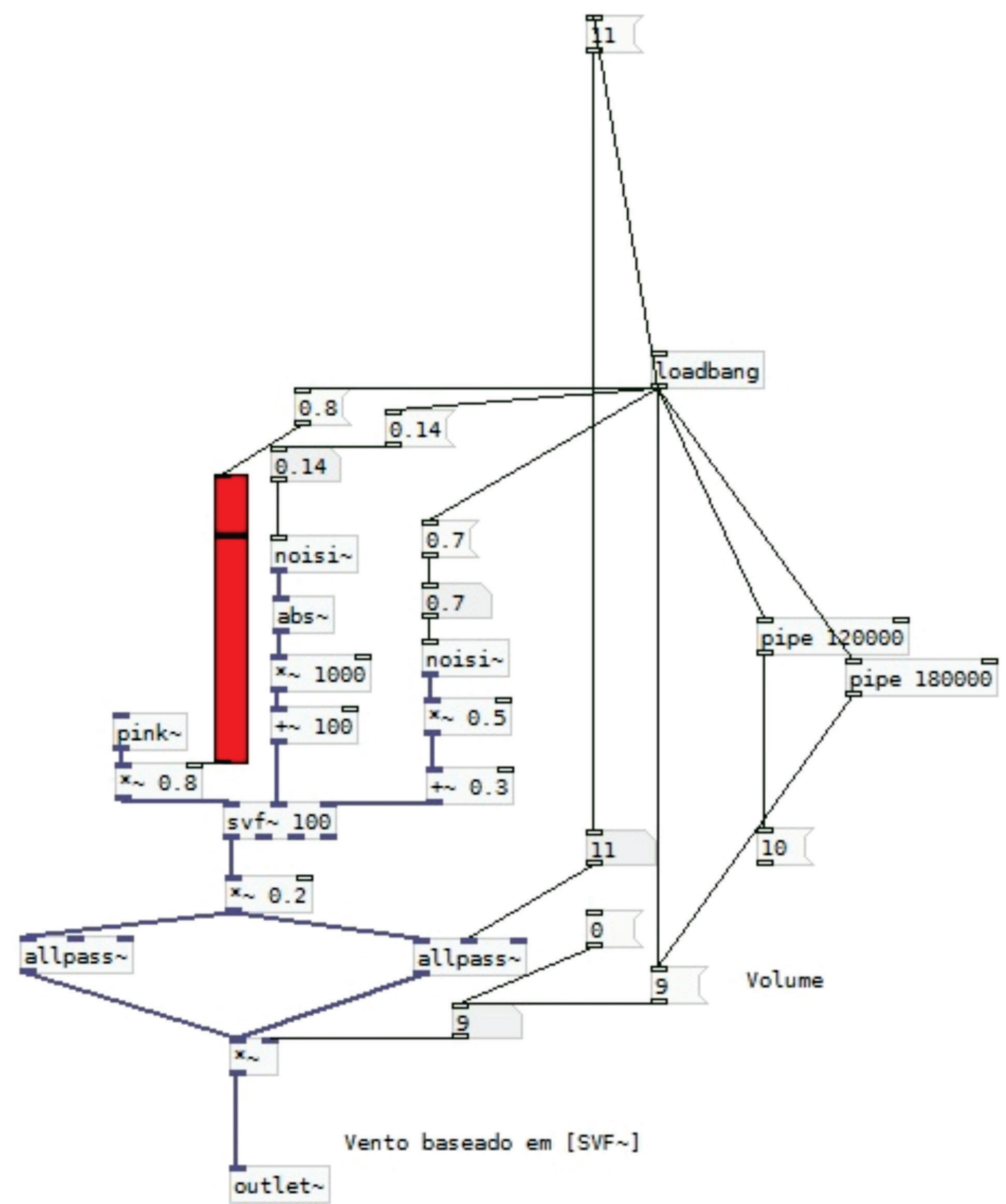

Figura 4: Imagem do segundo patch do projeto DP.

O terceiro patch é um modelo de aquisição de áudio digital que recebe os dados de um aplicativo VoIP (voz sobre protocolo de internet). Neste experimento, o VoIP utilizado foi o Skype um conhecido software de comunicação utilizado por milhões de usuários. Este permite a comunicação por voz em tempo-real de vários usuários simultaneamente. Toda a comunicação é feita pela internet. A proposta artística aqui apresentada utiliza dados de áudio de várias paisagens sonoras localizadas remotamente. Os dados desses ambientes são coletados em tempo-real e transmitido a um único local, através de uma conexão do VoIP em modo "conferência' (conference call), onde todos os dados de informação de todas as diversas paisagens sonoras são canalizados a um único fluxo de áudio. Este fluxo de áudio é recebido pelo terceiro patch (Figura 5) e mixado com o áudio resultante da síntese subtrativa do segundo patch, que é intuitivamente controlada em tempo real pelos gestos do per- 
former de DP. Os mesmos gestos também controlam a animação em tempo-real que é dinamicamente renderizada pelo primeiro patch. Juntos, estes três patches criam a experiência multimídia imersiva, dinâmica e ubíqua que se expressa na forma daquilo que é aqui chamado de meta-soundscape.

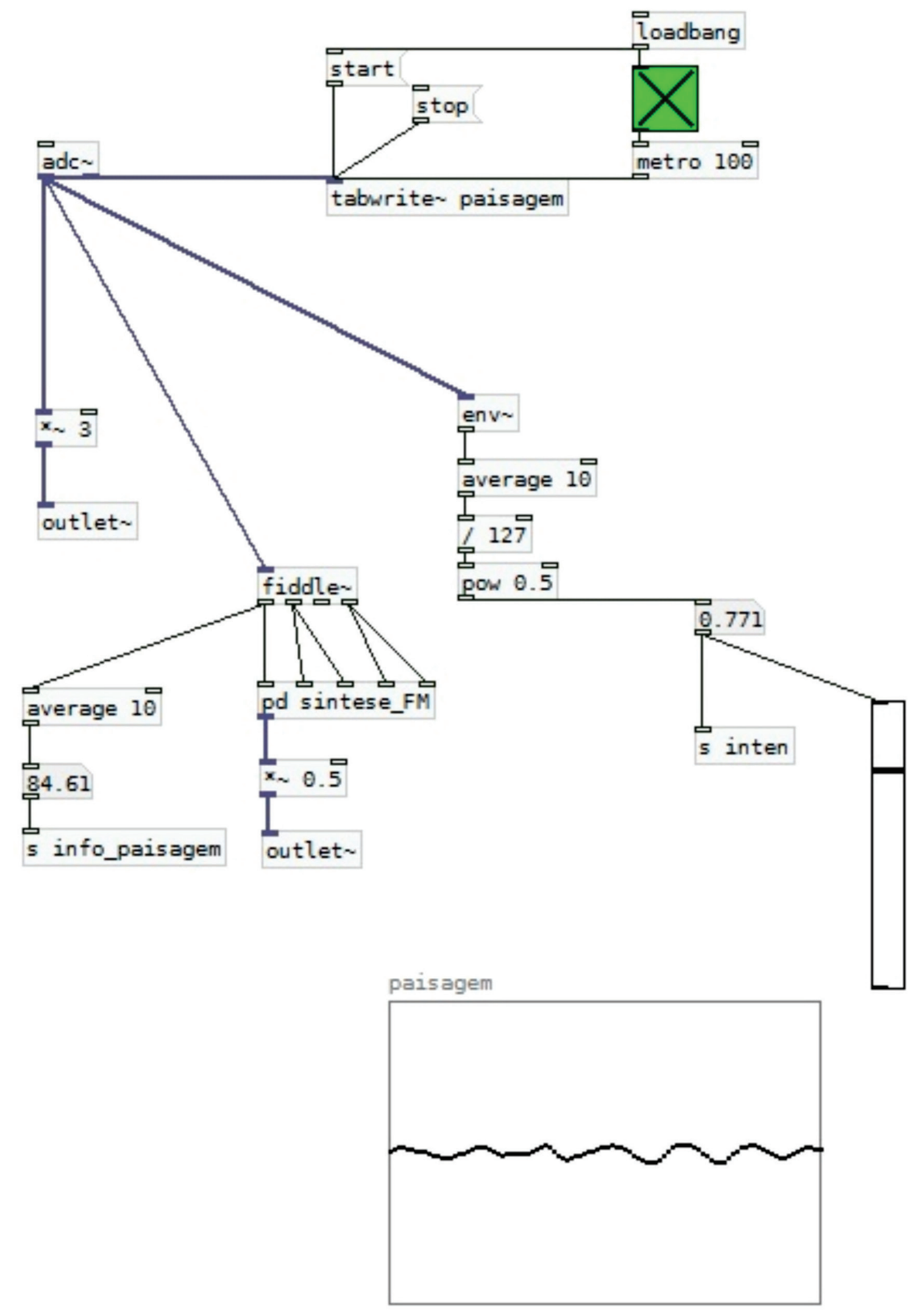

Figura 5: Imagem do terceiro patch do projeto DP. 


\section{A comunicação entre softwares}

Durante a implementação deste projeto, constatou-se que a comunicação de áudio entre Pd e VoIP não era uma tarefa trivial, como se imaginava a princípio, ao se utilizar o Pd em Linux. Ao pesquisar aplicações de softwares gratuitos e de código-livre que realizassem tal tarefa encontrou-se uma aplicação open-source simples, desenvolvida apenas para Windows, que foi capaz de realizar com sucesso a tarefa de comunicação de áudio entre estes softwares. Este aplicativo é denominado Virtual Audio Cable (VAC) ${ }^{2}$. Trata-se de um aplicativo gratuito capaz de transferir canais de áudio de um software para outro dentro do mesmo ambiente computacional. Podem existir outras aplicações disponíveis com função similar. No entanto, de todas aquelas testadas para Linux e Windows, apenas o VAC foi capaz de reconhecer e ser reconhecido pelo VoIP utilizado; o Skype. A fim de permitir a transferência de áudio do Skype para Pd através do VAC, deve-se criar dois "cabos virtuais" neste software, que apresenta diversas entradas e saídas para vários canais de áudio. Uma vez que estes cabos virtuais são criados, o Skype e o Pd são instantaneamente reconhecidos e conectados. Para a interação dos envolvidos foi utilizado uma rede de internet de alta velocidade (banda larga). Esta integração será aqui apresentada em forma de GUIs possuindo o objetivo de apresentar os mecanismos capazes de propiciar a interação do software Skype com a plataforma Pd. A figura a seguir demonstra um snapshot da integração destes três softwares (Pd, Skype e VAC) em execução e comunicando áudio entre si, em tempo-real.

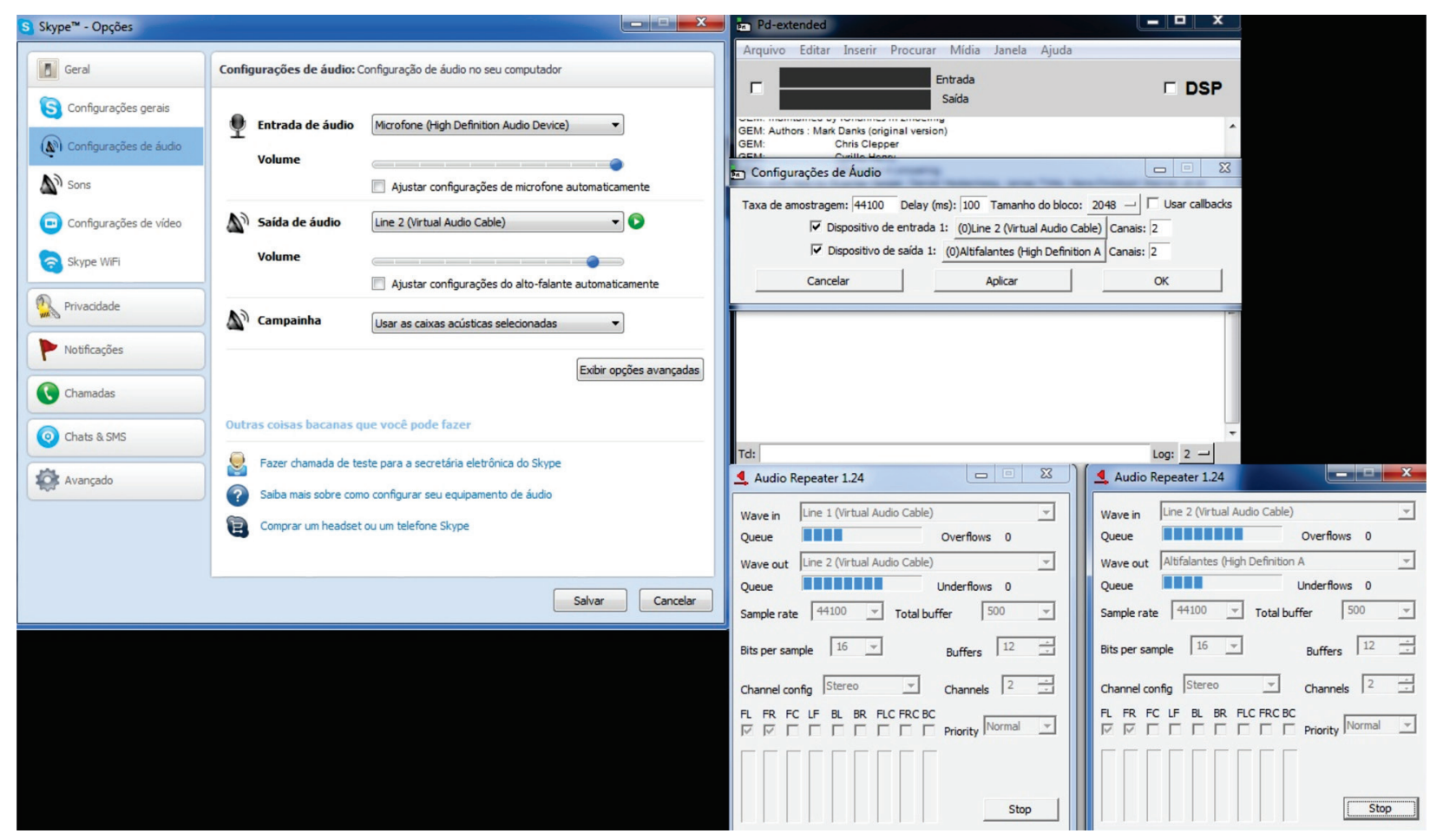

FigURA 6: Detalhe das GUls dos 3 sotwares que viabilizam a comunicação de áudio em tempo-real, que constituem o sistema computacional do projeto DP.

\section{Conclusão}

Este projeto teve como objetivo a exploração artística de criação do que é aqui referido pelo nome de "meta-soundscape"; uma paisagem sonora criada pelos dados de distantes e distintas paisagens sonoras, através da coleta e transmissão em tempo-real de seus even- 
tos sonoros. O objetivo almejado inicialmente neste projeto de investigar a possibilidade de unificar múltiplos soundscapes em um único local foi alcançado, através da superação das limitações físicas impostas pela localidade geográfica. Para tal, empregaram-se recursos tecnológicos que permitiram a redução virtual das distâncias entre paisagens sonoras localizadas remotamente criando um fluxo informacional sonoro, enviado para um único local onde a performance artística do projeto DP ocorre.

O fato de que contemporaneamente cada vez mais indivíduos estão se conectados através do cyberspace e compartilhando diversos tipos de dados, em distintos formatos e mídias, interagindo simultaneamente com múltiplos usuários, faz com que projetos artísticos como DP sejam uma consequência natural da exploração artística proporcionada pelos novos meios tecnológicos. Esta é uma performance artística multimodal, que pode futuramente ocorrer através das redes sociais da internet. Sua intenção estética não é pré-estabelecida, mas sim espontaneamente auto-organizada. Este se baseia num modelo computacional interativo que media várias paisagens sonoras remotamente localizadas. Os dados de áudio destas múltiplas paisagens sonoras são transmitidas através de VoIP, permitindo assim a criação de um meta-soundscape que é dinamicamente manipulado por um único performer. DP não pretende ser uma proposta iconoclasta, mas representar uma continuação e expansão da exploração artística do sistema de eco-composição. Enquanto este preserva a figura gerenciadora do artista, a composição é ao mesmo tempo fruto da interação e da colaboração de todos os eventos sonoros das paisagens sonoras distantes, que atuam como produtores de novas possibilidades e significados sonoros, expressos nos objetos da meta-soundscape resultante. Uma das premissas deste projeto é considerar o caos como facilitador de um processo auto-organizacional, que gera meta-soundscapes. Através de uma simples associação com o efeito borboleta, de Lorenz, este projeto também aceita e usa os resultados sonoros imprevisíveis, mantendo a natureza acústica típica das paisagens sonoras. O desenvolvimento computacional centrou na criação de uma interface modular capaz de gerenciar múltiplos fluxos de áudio, criando padrões sonoros que podem ser controlados em tempo-real, durante o período da performance. Este processo foi concebido e implementado por meio de uma interligação entre o modelo computacional de DP, composto pelo: Pd (em três patches), o VoIP (que viabiliza a coleta e a transmissão de dados de áudio) e o VCA (que permite a transferência que dados de áudio entre o VoIP e o Pd). O conceito de manipulação simultânea de várias paisagens sonoras estende a premissa inicialmente desbravada pela eco-composição, permitindo a exploração ubíqua de múltiplos fluxos de material sonoro, o que é aqui considerado como uma singela porém valiosa contribuição para futuras pesquisas acadêmicas e desenvolvimentos artísticos computacionais, para compositores de música contemporânea interativa.

\section{Notas}

1 http://www.koncon.nl/en/Departments\%20\%26\%20Study\%20Programmes/Sonology

2 http://www.virtualaudiocable.net

\section{Referência}

ASHBY, W. R. (1947). Principles of the self-organizing dynamic system. Journal of General Psychology 37: 125-128.

BARBOSA, A. 2010. Performance Musical em Rede. In: Criação musical e tecnologias: teoria e prática interdisciplinar, p. 188-208 - Goiânia: Anppom (Série Pesquisa em Música no Brasil, v. 2). ISBN: 978-85-63046-01-7. 
BARREIRO, D. L.; KELLER, D. (2010). “Composição com modelos sonoros: fundamentos e aplicações eletroacústicas”. In: Damián Keller e Rogério Budasz (ed.). Criação Musical e Tecnologias: Teoria e Prática Interdisciplinar. Goiânia: ANPPOM, p. 97-126. Disponível em: < http://anppom. com.br/editora/Pesquisa_em_Musica-02.pdf $>$.

BASANTA, A. (2010). Syntax as Sign: The use of ecological models within a semiotic approach to electroacoustic composition. Organised Sound 15, 125-132. (Doi: 10.1017/S1355771810000117.)

BURTNER, M. (2005). Ecoacoustic and shamanic technologies for multimedia composition and performance. Organised Sound 10(1), 3-19. (Doi: 10.1017/S1355771805000622.)

CHION, M. (1982) La musique électroacoustique. Paris: PUF (Presses Universitaires de France).

DENORA, T. (2003) After Adorno: Rethinking Music Sociology. Cambridge University Press. UK. 2003. p. 2-39.

FORNARI, J (2010) Percepção, Cognição e Afeto Musical. In: Anais do XX Congresso da ANPPOM. Criação Musical e Tecnologias: Teoria e Prática Interdisciplinar, CD-ROM.

FORNARI, J (2010) Interatividade Musical à Distância. Anais do $6^{\circ}$ Encontro de Música e Mídia. 15-17 Setembro 2010. ECA - USP

FORNARI, J. (2012). Designing Bodiless Musical Instruments. In: AES BRASIL 2012. 8-10 maio. Expo Center Norte. São Paulo. Anais... Brasil. 2012.

FURLANETE, F. P.; MAZOLLI, J.. Interações Musicais em Rede. In: X Simpósio Brasileiro de Computação e Música, 2005, Belo Horizonte. X Simpósio Brasileiro de Computação e Música. Belo Horizonte: Hugo Bastos de Paula, 2005. p. 325-328.

KELLER, D. (1999). Touch'n'go: Ecological Models in Composition. Master's Thesis in Interdisciplinary Arts, Simon Fraser University, Burnaby, BC, Canada. Disponível em: http:// www.sfu.ca/sonic-studio/srs/EcoModelsComposition/Title.html.

KELLER, D.; CAPASSO, A. (2000). Social and perceptual processes in the installation The Trade. Organised Sound 5(2), 85-94. (Doi: 10.1017/S1355771800002053.)

KELLER, D. (2000). Compositional processes from an ecological perspective. Leonardo Music Journal, 55-60. (Doi: 10.1162/096112100570459.) http://muse.jhu.edu/journals/leonardo_music_ journal/v010/10.1keller.pdf.

KELLER, D.; BARROS, A. E. B.; FARIAS, F. M.; NASCIMENTO, R. V.; PIMENTA, M. S.; FLORES, L. V.; MILETTO, E. M.; RADANOVITSCK, E. A. A.; SERAFINI, R. O. \& BARRAZA, J. F. (2009). Música ubíqua: conceito e motivação. In: Anais do Congresso da Associação Nacional de Pesquisa e Pós-Graduação em Música - ANPPOM (p. 539-542). Goiânia, GO: ANPPOM.

KELLER, D. (2004) Paititi: a multimodal journey to El Dorado. Tese de Doutorado em Artes Musicais. Stanford University. Stanford, CA. 2004. Disponível em: <https://ccrma.stanford. edu/ dkeller/pdf/Paititi2004.pdf $>$.

LOCKHART, A.; KELLER, D. (2006). Exploring cognitive process through music composition. In: Proceedings of the International Computer Music Conference (ICMC 2006) (p. 9-12). Ann Arbor, MI: MPublishing, University of Michigan Library. http:/quod.lib.umich.edu/cgi/p/pod/dod-idx/ exploring-cognitive-process-through-music-composition.pdf?c=icmc;idno=bbp2372.2006.026.

MANZOLLI, J. (1996) Auto-organização um Paradigma Composicional. In: Auto-Organização: Estudos Interdisciplinares, Campinas, CLE/Unicamp, ed. Debrun, M. Gonzales, M.E.Q. Pessoa Jr. O. 1996. p.417-435. 
NAVEIRA, R. B. (1998) Caos e complexidade nas organizações. Dissertação de Mestrado. Departamento de Engenharia da Universidade Federal do Rio de Janeiro. Rio de Janeiro: UFRJ.

PIMENTA, M. S., FLORES, L. V., CAPASSO, A., TINAJERO, P. \& KELLER, D. (2009). Ubiquitous music: concept and metaphors. In Proceedings of the Brazilian Symposium on Computer Music (XII SBCM) (p. 139-150). Recife, PE: SBC.

PUCKETTE, M. (1996). Pure Data. Proceedings of the 1996 International Computer Music Con ference (p. 269 -272), San Francisco: International Computer music Association.

RADANOVITSCK, E. A. A., KELlER, D., FlORES, L. V., PIMENTA, M. S. \& QUEIROZ, M. (2011). mixDroid: Marcação temporal para atividades criativas. In: Proceedings of the XIII Brazilian Symposium on Computer Music (SBCM 2011). Vitória, ES: SBC. http://compmus.ime. usp.br/sbcm/2011.

SCHAFER, R. M. (2001) A afinação do mundo. São Paulo: Ed. UNESP.

SMALLEY, D. (1990) Spectro-morphology and Structuring Processes in the Language of Electroacoustic Music, ed. Emmerson, 1990. p. 61-93.

TRAUB, P. (2005) Sounding the Net: Recent Sonic Works for the Internet and Computer Networks. Contemporary Music Review. Vol. 24, 2005. p. 459 - 481.

TRUAX, B. (1992). "Electroacoustic Music and the Soundscape: The inner and the Outer World". In: Paynter, John. Companion to Contemporary Musical Thought. Routledge. pp. 374-398.

TRUAX, B. (2002). Genres and techniques of soundscape composition as developed at Simon Fraser University. Organised Sound 7(1), 5-14. (Doi: 10.1017/S1355771802001024.)

WEISER, M. (1991) The Computer for the Twenty-First Century. Scientific American, v. 265, n. 3, 1991. p. 94-101.

WESTERKAMP, H. (2002). Linking soundscape composition and acoustic ecology. Organised Sound 7, 51-56. (Doi: 10.1017/S1355771802001085.)

\section{Websites}

Primeira performance do projeto DP [Internet]. Campinas/SP (Brasil): 2013 [em Setembro de 2013]. Disponível em: http://youtu.br/xtxr2XMaM18

Luzilei Aliel - Educador, músico e compositor. Tem desenvolvido trabalho na área de tecnologia, música contemporânea e educação. Possui licenciatura em educação musical pela UFSCar (2012) onde foi bolsista CNPq de iniciação científica.

José Fornari - Desde 2008, pesquisador, carreira PQ, no NICS (Núcleo Interdisciplinar de Comunicação Sonora) da UNICAMP. Realizou um Pos-doutorado (2007) em Cognição Musical, no grupo MMT (Music and Mind Tecnhology) da Universidade de Jyvaskyla, Finlândia, e anteriormente outro Pos-doutorado (2004) em Síntese Sonora Evolutiva, com bolsa da FAPESP. É Mestre (1994) e Doutor (2003) pela FEEC/UNICAMP. Tem bacharelado em Música Popular (1993) pelo Departamento de Música do IA / UNICAMP e Engenharia Elétrica (1991) pela FEEC / UNICAMP. Desde 2013 é diretor educacional do Museu Exploratório de Ciências da UNICAMP. 